\title{
Surface Tension and Density Measurements of Sn-Ag-Sb Liquid Alloys and Phase Diagram Calculations of the Sn-Ag-Sb ternary system
}

\author{
Zbigniew Moser ${ }^{1}$, Władysław Gassior ${ }^{1}$, Janusz Pstruśs ${ }^{1}$, Satoru Ishihara ${ }^{2}$, Xing Jun Liu ${ }^{3}$, \\ Ikuo Ohnuma ${ }^{3}$, Ryosuke Kainuma ${ }^{3}$ and Kiyohito Ishida ${ }^{3}$ \\ ${ }^{1}$ Institute of Metallurgy and Materials Science, Polish Academy of Sciences, 30-059 Krakow, Reymonta Street 25, Poland \\ ${ }^{2} R \& D$ Institute of Metals and Composites for Future Industries, Sendai 980-8577, Japan \\ ${ }^{3}$ Department of Materials Science, Graduate School of Engineering, Tohoku University, Sendai 980-8579, Japan
}

\begin{abstract}
The maximum bubble pressure method has been used to measure the surface tension of pure antimony and the surface tension and density (dilatometric method) of Sn-3.8 at\% Ag eutectic base alloys with 0.03, 0.06 and 0.09 molar fraction of antimony at a temperature range from 550 to $1200 \mathrm{~K}$. The linear dependencies of surface tension and density on temperature were observed and they were described by straight-line equations. Moreover, experimental determination of phase diagram and thermodynamic calculations in the Sn-Ag-Sb system were performed and the resulting optimized thermodynamic parameters were used for modeling of the surface tension. In addition, a non-equilibrium solidification process using the Scheil model was simulated and compared with the equilibrium solidification behavior of a Sn-Ag-Sb alloy.
\end{abstract}

(Received November 6, 2003; Accepted January 26, 2004)

Keywords: lead-free solder, microsoldering, thermodynamics, calphad

\section{Introduction}

In 1999 a co-operation program on $\mathrm{Pb}$-free soldering materials of Institute of Metallurgy and Materials Science in Poland and Tohoku University in Japan has been initiated. In Poland, experimental studies were focused on physical properties like surface tension, viscosity and density, while in Japan measurements of phase equilibria were performed. The latter, combined with assessed thermodynamic data were used for obtaining the optimized thermodynamic parameters. Optimized thermodynamic parameters are the starting point for verification of existing phase equilibria or for calculation of new phase equilibria and for modeling of physical properties.

Examples of such trends were published jointly in the case of $\mathrm{Ag}-\mathrm{In}^{1)}$ and $\mathrm{Sn}-\mathrm{Ag}-\mathrm{In}^{2)}$ liquid alloys. The separate experimental studies ${ }^{3)}$ in Krakow on surface tension and density on binary low melting eutectics and on third additions to binary eutectics have shown that the comparison of the surface tension with the values calculated from optimized thermodynamic parameters is reliable. However, the temperature dependence of the surface tension is always linear, while the modeled results by the Butler's model ${ }^{4)}$ are curvilinear. The reason is not yet explained, and in addition in the case of simple eutectic systems like $\mathrm{Ag}-\mathrm{Bi}^{5)}$ even the opposite trend (lowering of the surface tension with temperature) was observed. It was proved that these limitations of the Butler's model are not connected with optimized thermodynamic parameters, but rather in some assumptions in this model. ${ }^{5)}$

It should be noted that most of the studies on $\mathrm{Pb}$-free soldering materials is limited to ternary alloys based on tin, but as they do not satisfy physical properties, mechanical properties and wettability when comparing with traditional $\mathrm{Pb}-\mathrm{Sn}^{6}$ ) alloys, the nowadays studies are focused on multicomponent systems. The most promising candidates to replace $\mathrm{Pb}-\mathrm{Sn}$ solders are eutectic alloys $\mathrm{Sn}-\mathrm{Ag}^{7)}$ and $\mathrm{Sn}$ Ag-Cu. ${ }^{8)}$
While in Ref. 8 it was confirmed that $\mathrm{Cu}$ addition increases the surface tension of eutectic Sn-Ag alloy and therefore only small amounts of $\mathrm{Cu}$ are considered, in Ref. 9 the main interest was stressed on phase equilibria and on equilibrium and non-equilibrium solidification processes using the Scheil model as well as on the prediction of the melting equilibria when adding various amounts of In and $\mathrm{Bi}$ to the ternary eutectic Sn-Ag-Cu. Simulation calculations of quaternary and quinary additions are important for the design of new $\mathrm{Pb}$ free soldering materials including also the sequence of the formation of intermetallic compounds on the $\mathrm{Cu}$ substrate. It was noted by Lee et l. $^{10)}$ that the first forming intermetallic compound plays the most important role in the soldering process and the prediction is possible when combing thermodynamics with diffusion.

The main aim of these joint studies is to correlate experimental surface tension with calculations by means of Butler's model using optimized thermodynamic parameters. In parallel, solidification simulation was performed and the change of the terminating temperatures of solidification was analyzed.

\section{Experimental Procedure}

\subsection{Determination of phase equilibria}

Ternary $\mathrm{Sn}-\mathrm{Ag}-\mathrm{Sb}$ alloys were prepared using pure tin (99.99\%), silver (99.99\%) and antimony (99.99\%) in evacuated transparent quartz capsules at $1073 \mathrm{~K}$ for $3 \mathrm{~h}$. Specimens were equilibrated at $373 \mathrm{~K}$ for $40 \mathrm{~d}$ and then quenched in iced water. Microstructure examination of each specimen was carried out by optical microscopy. Equilibrium compositions in multiphase specimens were determined by electron probe microanalysis (EPMA). Liquidus temperatures and phase transformation temperatures were also determined by differential scanning calorimetry (DSC), which was carried out in an atmosphere of flowing argon. The samples were heated and cooled at rates of $3 \mathrm{~K} / \mathrm{min}$ in a sealed copper pan. An empty copper pan with a lid was used 


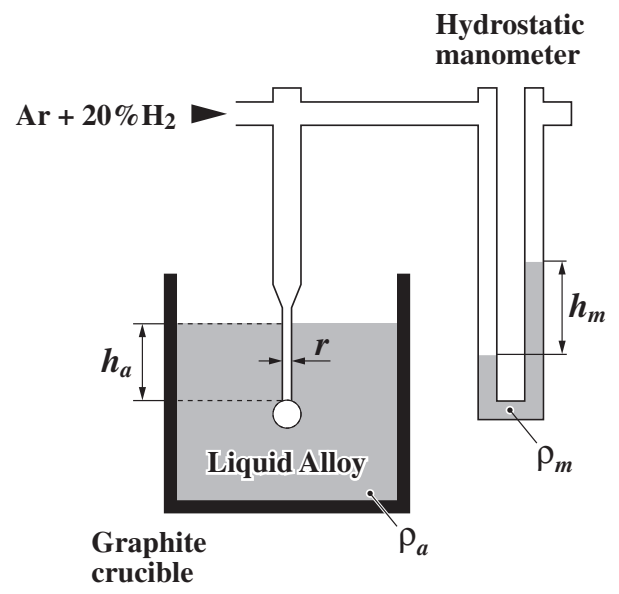

Fig. 1 Experimental arrangements for surface tension measurements by the maximum bubble pressure method.

as a reference. The data are taken from heating curve.

\subsection{Surface tension and density measurements}

The maximum bubble pressure method was used in the surface tension measurements. The method is based on the known capillarity equation:

$$
\sigma=\frac{1}{2} r \Delta p \quad(\mathrm{~N} / \mathrm{m})
$$

describing the relation between the surface tension $\sigma$, the radius of the capillary $r$ and the pressure $\Delta p$ necessary to form and to detach the gas bubble from the end of the capillary. The $\Delta p$ is, in fact, the pressure difference between the gas pressure and the hydrostatic pressure of the liquid alloy and it is given by the following equation:

$$
\begin{aligned}
\Delta p & =p_{\mathrm{g}}-p_{\mathrm{a}} \quad\left(\mathrm{N} / \mathrm{m}^{2}\right) \\
\Delta p & =\mathrm{g}\left(\rho_{\mathrm{m}} h_{\mathrm{m}}-\rho_{\mathrm{a}} h_{\mathrm{a}}\right) \quad\left(\mathrm{N} / \mathrm{m}^{2}\right)
\end{aligned}
$$

where; $p_{\mathrm{g}}$ - the gas pressure, $p_{\mathrm{a}}$ - the hydrostatic pressure, $\mathrm{g}$ - the acceleration of gravity, $\rho_{\mathrm{a}}$ and $\rho_{\mathrm{m}}$ - the density of the investigated liquid alloy and manometer liquid, $h_{\mathrm{a}}$ - the immersion depth of the capillary and $h_{\mathrm{m}}$ - the height of the manometer liquid. Scheme of the experimental set for measuring of the surface tension is shown in Fig. 1. The surface tension calculated from eq. (1) presents the approximate value, thus, the exact values of surface tensions were calculated using the procedure proposed by Sugden. ${ }^{11)}$

Densities of the $(\mathrm{Sn}-\mathrm{Ag})_{\mathrm{eu}}+\mathrm{Sb}$ liquid alloys were measured by the dilatometric method (shown schematically in Fig. 2) based on the measurement of the height of constant weight of the alloy in the crucible of the diameter $D$. The density is calculated from the following equation:

$$
\begin{aligned}
& \rho=\frac{m}{V} \\
& V=\frac{\pi D^{2} H}{4}
\end{aligned}
$$

In eqs. (4) and (5) $\rho$ is the density, $m$ - the weight of alloy, $V$ - the volume of the alloy, $D$ - the crucible diameter and $H$ - the height of the alloy in the crucible. The correction on the thermal expansion of the crucible was made at each

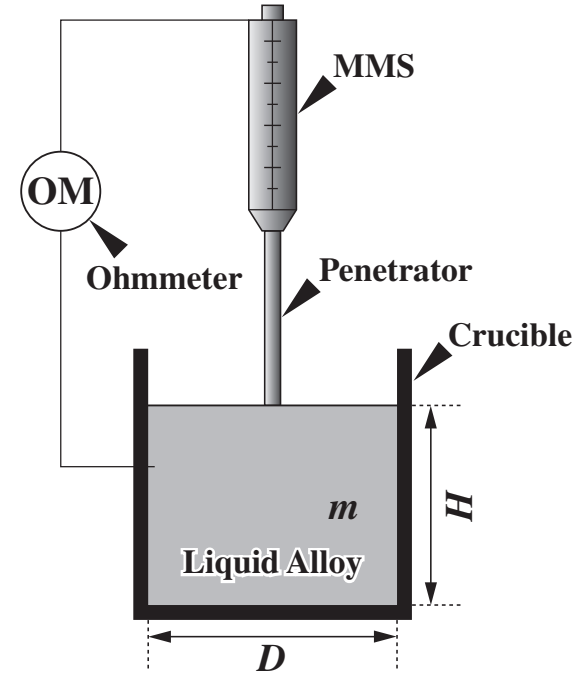

Fig. 2 Experimental scheme for density measurements by the dilatometric method. MMS denotes micrometer screw.

measurement temperature.

The maximum bubble pressure method has been used to measure the surface tension of pure antimony and the surface tension and density (dilatometric method) of Sn-3.8 at\% Ag eutectic base alloys with $0.03,0.06$ and 0.09 molar fraction of antimony at a temperature range from 550 to $1250 \mathrm{~K}$.

The $(\mathrm{Sn}-\mathrm{Ag})_{\mathrm{eu}}+\mathrm{Sb}$ alloys were prepared by melting in a graphite crucible an appropriate amount of tin (99.999 at\%), silver (99.995 at\%) and antimony (99.999 at\%) directly before measurements. The protective atmosphere of high purity gas mixture of Ar-20 vol. $\% \mathrm{H}_{2}$ was used in measurements of both surface tension and density.

\section{Thermodynamic Models}

\subsection{Description of Gibbs energy}

The Gibbs energy of solution phases, such as liquid, (Ag): $\mathrm{fcc}, \zeta$ : hcp, $\beta$-SbSn: B1, $(\beta \mathrm{Sn})$ : bct and (Sb): rhombohedral phases are described by the subregular solution model as follows:

$$
\begin{aligned}
G_{\mathrm{m}}^{\varphi}= & x_{\mathrm{Ag}}^{\varphi}{ }^{\circ} G_{\mathrm{Ag}}^{\varphi}+x_{\mathrm{Sb}}^{\varphi}{ }^{\circ} G_{\mathrm{Sb}}^{\varphi}+x_{\mathrm{Sn}}^{\varphi}{ }^{\circ} G_{\mathrm{Sn}}^{\varphi} \\
& +R T\left(x_{\mathrm{Ag}}^{\varphi} \ln x_{\mathrm{Ag}}^{\varphi}+x_{\mathrm{Sb}}^{\varphi} \ln x_{\mathrm{Sb}}^{\varphi}+x_{\mathrm{Sn}}^{\varphi} \ln x_{\mathrm{Sn}}^{\varphi}\right) \\
& +{ }^{\mathrm{ex}} G_{\mathrm{m}}^{\varphi}
\end{aligned}
$$

where ${ }^{\circ} G_{i}^{\varphi}$ and $x_{\dot{1}}^{\varphi}$ are the molar Gibbs energy and the mole fraction of the pure component i in $\varphi$ phase, respectively. $R$ is the gas constant and $T$ is the absolute temperature. The term ${ }^{\text {ex }} G_{\mathrm{m}}^{\varphi}$ consists of the binary excess Gibbs energy described by the Redich-Kister polynomial and the ternary one, extrapolation from the binary energies by Muggianu formula and ternary interaction as follows;

$$
\begin{aligned}
{ }^{e x} G_{\mathrm{m}}^{\varphi}= & x_{\mathrm{Ag}}^{\varphi} x_{\mathrm{Sb}}^{\varphi} L_{\mathrm{Ag}, \mathrm{Sb}}^{\varphi}+x_{\mathrm{Ag}}^{\varphi} x_{\mathrm{Sn}}^{\varphi} L_{\mathrm{Ag}, \mathrm{Sn}}^{\varphi}+x_{\mathrm{Sb}}^{\varphi} x_{\mathrm{Sn}}^{\varphi} L_{\mathrm{Sb}, \mathrm{Sn}}^{\varphi} \\
& +x_{\mathrm{Ag}}^{\varphi} x_{\mathrm{Sb}}^{\varphi} x_{\mathrm{Sn}}^{\varphi}\left(x_{\mathrm{Ag}}^{\varphi}{ }^{0} L_{\mathrm{Ag}, \mathrm{Sb}, \mathrm{Sn}}^{\varphi}+x_{\mathrm{Sb}}^{\varphi}{ }^{1} L_{\mathrm{Ag}, \mathrm{Sb}, \mathrm{Sn}}^{\varphi}\right. \\
& \left.+x_{\mathrm{Sn}}^{\varphi}{ }^{2} L_{\mathrm{Ag}, \mathrm{Sb}, \mathrm{Sn}}^{\varphi}\right)
\end{aligned}
$$

The Gibbs energy of the stoichiometric compound, $\mathrm{Sb}_{2} \mathrm{Sn}_{3}$ phase, is described as following function; 


$$
G_{\mathrm{m}}^{\mathrm{Sb}_{2} \mathrm{Sn}_{3}}=0.4^{\circ} G_{\mathrm{Sb}}^{\mathrm{rho}}+0.6^{\circ} G_{\mathrm{Sn}}^{\mathrm{bct}}+\Delta G^{\mathrm{f}}
$$

where $\Delta G^{\mathrm{f}}$ is the Gibbs energy of formation of the $\mathrm{Sb}_{2} \mathrm{Sn}_{3}$ phase and ${ }^{\circ} G_{\mathrm{Sb}}^{\text {rho }}$ and ${ }^{\circ} G_{\mathrm{Sn}}^{\mathrm{bct}}$ are the molar Gibbs energy of the respective reference states of antimony (rhombohedral) and tin (bct). The orthorhombic $\varepsilon$ phases, $\mathrm{Ag}_{3} \mathrm{Sb}$ and $\mathrm{Ag}_{3} \mathrm{Sn}$, have mutual solubility, and are modeled as $(\mathrm{Ag}, \mathrm{Sb})_{0.75}(\mathrm{Ag}, \mathrm{Sb}$, $\mathrm{Sn})_{0.25}$ by a two sublattice formula. The Gibbs energy is described as follows;

$$
\begin{aligned}
G_{\mathrm{m}}^{\varepsilon}= & y_{\mathrm{Ag}}^{\mathrm{I}} y_{\mathrm{Ag}}^{\mathrm{II}} G_{\mathrm{Ag}: \mathrm{Ag}}^{\varepsilon}+y_{\mathrm{Sb}}^{\mathrm{I}} y_{\mathrm{Sb}}^{\mathrm{II}} G_{\mathrm{Sb}: \mathrm{Sb}}^{\varepsilon} \\
& +y_{\mathrm{Ag}}^{\mathrm{I}} y_{\mathrm{Sb}}^{\mathrm{II}} G_{\mathrm{Ag}: \mathrm{Sb}}^{\varepsilon}+y_{\mathrm{Ag}}^{\mathrm{I}} y_{\mathrm{Sn}}^{\mathrm{II}} G_{\mathrm{Ag}: \mathrm{Sn}}^{\varepsilon} \\
& +y_{\mathrm{Sb}}^{\mathrm{I}} y_{\mathrm{Ag}}^{\mathrm{II}} G_{\mathrm{Sb}: \mathrm{Ag}}^{\varepsilon}+y_{\mathrm{Sb}}^{\mathrm{I}} y_{\mathrm{Sn}}^{\mathrm{II}} G_{\mathrm{Sb}: \mathrm{Sn}}^{\varepsilon} \\
& +0.75 R T\left(y_{\mathrm{Ag}}^{\mathrm{I}} \ln y_{\mathrm{Ag}}^{\mathrm{I}}+y_{\mathrm{Sb}}^{\mathrm{I}} \ln y_{\mathrm{Sb}}^{\mathrm{I}}\right) \\
& +0.25 R T\left(y_{\mathrm{Ag}}^{\mathrm{II}} \ln y_{\mathrm{Ag}}^{\mathrm{II}}+y_{\mathrm{Sb}}^{\mathrm{II}} \ln y_{\mathrm{Sb}}^{\mathrm{II}}\right. \\
& \left.+y_{\mathrm{Sn}}^{\mathrm{II}} \ln y_{\mathrm{Sn}}^{\mathrm{II}}\right)+{ }^{\mathrm{ex}} G_{\mathrm{m}}^{\varepsilon}
\end{aligned}
$$

where $G_{\mathrm{A}: \mathrm{B}}^{\varepsilon}$ is the molar Gibbs energy of the stable or hypothetical $\varepsilon-\mathrm{A}_{3} \mathrm{~B}$ phase and $y_{\mathrm{A}}^{\mathrm{N}}$ denote the site fraction of element $\mathrm{A}$ in the Nth sublattice.

\subsection{Modeling of surface tension}

In 1932 Butler $^{4)}$ considering the equilibrium between a bulk phase and a monolayer at the surface, regarded as an individual phase, derived the relation allowing to calculate the surface tension of the alloys, which for the liquid Sn-Ag$\mathrm{Sb}$ alloys has the following form:

$$
\begin{aligned}
\sigma & =\sigma_{\mathrm{Ag}}+\frac{R T}{A_{\mathrm{Ag}}} \ln \frac{x_{\mathrm{Ag}}^{\mathrm{S}}}{x_{\mathrm{Ag}}^{\mathrm{B}}}+\frac{1}{A_{\mathrm{Ag}}}\left({ }^{\mathrm{ex}} \bar{G}_{\mathrm{Ag}}^{\mathrm{S}}-{ }^{\mathrm{ex}} \bar{G}_{\mathrm{Ag}}^{\mathrm{B}}\right) \\
& =\sigma_{\mathrm{Sb}}+\frac{R T}{A_{\mathrm{Sb}}} \ln \frac{x_{\mathrm{Sb}}^{\mathrm{S}}}{x_{\mathrm{Sb}}^{\mathrm{B}}}+\frac{1}{A_{\mathrm{Sb}}}\left({ }^{\mathrm{ex}} \bar{G}_{\mathrm{Sb}}^{\mathrm{S}}-{ }^{\mathrm{ex}} \bar{G}_{\mathrm{Sb}}^{\mathrm{B}}\right) \\
& =\sigma_{\mathrm{Sn}}+\frac{R T}{A_{\mathrm{Sn}}} \ln \frac{x_{\mathrm{Sn}}^{\mathrm{S}}}{x_{\mathrm{Sn}}^{\mathrm{B}}}+\frac{1}{A_{\mathrm{Sn}}}\left({ }^{\mathrm{ex}} \bar{G}_{\mathrm{Sn}}^{\mathrm{S}}-{ }^{\mathrm{ex}} \bar{G}_{\mathrm{Sn}}^{\mathrm{B}}\right)
\end{aligned}
$$

Equation (10) relates the surface tension of the solution with this property of pure metals as well as with the surface area of the metallic monolayer and excess Gibbs energies of the components in the surface and the bulk phases.

In eq. (10), $\sigma_{\mathrm{Ag}}, \sigma_{\mathrm{Sb}}$ and $\sigma_{\mathrm{Sn}}$ are the surface tensions of pure silver, antimony and tin in $(\mathrm{mN} / \mathrm{m}), A_{\mathrm{i}}$ is the molar surface area in a monolayer of pure liquid $\mathrm{i}(\mathrm{i}=\mathrm{Ag}, \mathrm{Sb}, \mathrm{Sn})$ in $\left(\mathrm{m}^{2}\right)$, $x_{\mathrm{Ag}}, x_{\mathrm{Sb}}, x_{\mathrm{Sn}}$ are the mole fractions of $\mathrm{Ag}, \mathrm{Sb}$ and $\mathrm{Sn}$ in the surface and the bulk phase, respectively and ${ }^{\text {ex }} \bar{G}_{\mathrm{i}}^{\mathrm{S}}$ and ${ }^{\mathrm{ex}} \bar{G}_{\mathrm{i}}^{\mathrm{B}}$ are the partial excess Gibbs energies of the component $i$ in the surface and bulk phase. The molar surface area, $A_{\mathrm{i}}$ is calculated from the equation:

$$
A_{\mathrm{i}}=L N^{1 / 3} V_{\mathrm{i}}^{2 / 3} \quad\left(\mathrm{~m}^{2}\right)
$$

In eq. (11), $N$ is Avogadro's number, and $V_{\mathrm{i}}$ is the molar volume of pure liquid i in $\left(\mathrm{m}^{3}\right), L$ is usually set to be 1.091 for liquid metals assuming close packed structures. ${ }^{12)}$

Finally, the relationship between excess Gibbs energy of component $\mathrm{i}$ in bulk and surface phases is assumed to be equal as follows:

$$
{ }^{\mathrm{ex}} \bar{G}_{\mathrm{i}}^{\mathrm{S}}=\beta^{\mathrm{ex}} \bar{G}_{\mathrm{i}}^{\mathrm{B}} \quad(\mathrm{J} / \mathrm{mol})
$$

$\beta$ is a parameter corresponding to the ratio of the coordination number $Z$ in the surface phase to that in the bulk phase $Z^{\mathrm{S}} / Z^{\mathrm{B}}$ and is assumed to be equal to 0.83 for liquid. $^{13,14)}$

\section{Results and Discussion}

\subsection{Determination of phase equilibria}

Typical microstructures of Sn-30Ag- $x \mathrm{Sb}$ (mass\%); (a) $x=15$, (b) $x=35$, and (c) $x=50$ alloys equilibrated at $373 \mathrm{~K}$ for $40 \mathrm{~d}$ are shown in Fig. 3. In this isothermal section, a two-phase and two three-phase microstructures were obtained. The equilibrium compositions determined by EPMA are listed in Table 1. Transition temperatures in isopleth sections at $8 \mathrm{Ag}, 30 \mathrm{Ag}, 10 \mathrm{Sn}$ and $15 \mathrm{Sb}$ (mass\%) were also measured by DSC as listed in Table 2.

Table 1 Equilibrium composition at $373 \mathrm{~K}$ in the $\mathrm{Sn}-\mathrm{Ag}-\mathrm{Sb}$ system.

\begin{tabular}{cccccccc}
\hline Equilibrium Relation & \multicolumn{6}{c}{ Composition (mass\%) } \\
\hline \multirow{2}{*}{ Phase 1/Phase 2/Phase 3 } & \multicolumn{2}{c}{ Phase 1} & Phase 2 & \multicolumn{2}{c}{ Phase 3 } \\
\cline { 2 - 8 } & $\mathrm{Ag}$ & $\mathrm{Sb}$ & $\mathrm{Ag}$ & $\mathrm{Sb}$ & $\mathrm{Ag}$ & $\mathrm{Sb}$ \\
\hline$\beta-\mathrm{SbSn} / \varepsilon-\mathrm{Ag}_{3}(\mathrm{Sb}, \mathrm{Sn}) /(\beta \mathrm{Sn})$ & 0.3 & 41.5 & 70.0 & 2.0 & 1.7 & 3.6 \\
$\beta-\mathrm{SbSn} / \varepsilon-\mathrm{Ag}_{3}(\mathrm{Sb}, \mathrm{Sn}) /-$ & 0.4 & 50.7 & 72.3 & 10.5 & - & - \\
$\beta-\mathrm{SbSn} / \varepsilon-\mathrm{Ag}_{3}(\mathrm{Sb}, \mathrm{Sn}) /(\mathrm{Sb})$ & 1.3 & 59.0 & 71.9 & 14.5 & 0.2 & 90.4 \\
\hline
\end{tabular}

(a) Sn-30Ag-15Sb

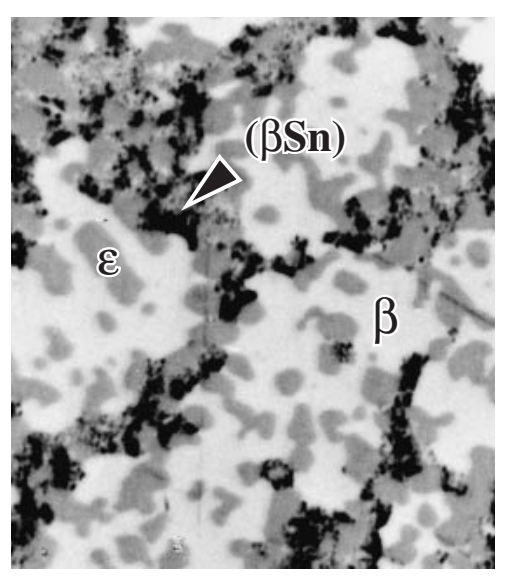

(b) Sn-30Ag-35Sb

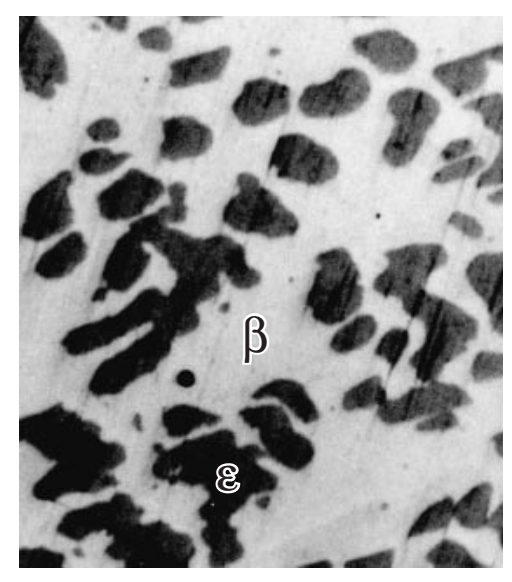

(c) Sn-30Ag-50Sb (mass \%)

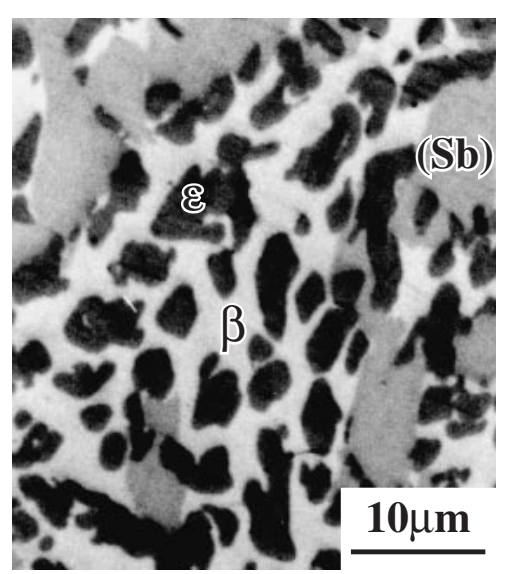

Fig. 3 Optical microstructures of (a) Sn-30Ag-15Sb, (b) Sn-30Ag-35Sb and (c) Sn-30Ag-50Sb (mass \%) equilibrated at $373 \mathrm{~K}$ for $40 \mathrm{~d}$. 
Table 2 Transformation temperatures determined by DSC.

\begin{tabular}{|c|c|c|c|}
\hline \multicolumn{2}{|c|}{ Alloy composition (mass\%) } & \multirow{2}{*}{ Liquidus/K } & \multirow{2}{*}{$\begin{array}{c}\text { Other transformation } \\
\text { temperature } / \mathrm{K}\end{array}$} \\
\hline $\mathrm{Ag}$ & $\mathrm{Sb}$ & & \\
\hline 8.0 & 37.4 & 652 & $623,596,581,507$ \\
\hline 30.0 & 15.0 & 710 & $595,586,506$ \\
\hline 30.0 & 28.4 & 704 & $643,581,505$ \\
\hline 30.0 & 50.0 & 734 & 710,650 \\
\hline
\end{tabular}

\subsection{Optimization of phase equilibria \\ 4.2.1 Binary systems}

The phase diagram of the Ag-Sb binary system was evaluated by Lee et al., ${ }^{15)}$ and later, Oh et al. ${ }^{16)}$ made reevaluation taking into account low temperature equilibria and heats of formation of the solid phases. The thermodynamic assessment of the Ag-Sn binary system has been carried out by Karakaya and Thompson, ${ }^{17)}$ Chevalier, ${ }^{18)}$ Kattner and Boettinger, ${ }^{19)}$ Oh et $a l .{ }^{16)}$ and Ohtani et al. ${ }^{20)}$ The result of the assessment of Kattner and Boettinger ${ }^{19)}$ seems to be quite satisfactory except for the lattice stability of the metastable hcp tin phase, ${ }^{\circ} G_{\mathrm{Sn}}^{\mathrm{hcp}}$, which causes inconsistency with the hypothetical melting temperature extrapolated from high pressure measurement as pointed out by Ohtani et al. ${ }^{21)}$ They adopted ${ }^{\circ} G_{\mathrm{Sn}}^{\mathrm{hcp}}$ proposed by Karakaya and Thompson ${ }^{17)}$ to the Kattner's assessment and re-evaluated the interaction parameter of the $\zeta$ : hcp phase, $L_{\mathrm{Ag}, \mathrm{Sn}}^{\mathrm{hcp}} \cdot{ }^{20)}$ Jönnson and Ågren, ${ }^{22)}$ and Ohtani et al. ${ }^{21)}$ evaluated the thermodynamic parameter of the $\mathrm{Sb}-\mathrm{Sn}$ binary system. Both of them yield satisfactory results, however, some lattice stability parameters in the former assessment are different from those in a recent compilation by Dinsdale. ${ }^{23)}$ In the later assessment, the Gibbs energy of the $\beta$ SbSn: B1 ordered phase was formulated by the two-sublattice model and the parameters involving both an ordering and a disordering contributions were evaluated. However, the calculation seemed to be performed under the disordered configuration. Then, the phase diagram cannot be reproduced correctly in the B1 ordered condition with their thermodynamic parameters. In this study, the Gibbs energy of the $\beta$ SbSn: B1 phase is described in the sub-regular solution model taking into account the disordering contribution of the evaluated parameters by Ohtani et al. ${ }^{20)}$ In the present assessment, thermodynamic parameters were taken from those of the $\mathrm{Ag}-\mathrm{Sb},{ }^{16)} \mathrm{Ag}-\mathrm{Sn}^{17,20)}$ and $\mathrm{Sb}-\mathrm{Sn}^{21)}$ binary systems. The calculated binary phase diagrams are shown in Fig. 4.

\subsubsection{Sn-Ag-Sb ternary system}

The enthalpy of mixing in the liquid phase was measured by Gather et al. ${ }^{24)}$ Masson and Kirkpatrick measured transition temperatures on some isopleth section by differential thermal analysis (DTA). ${ }^{25)}$ In addition to these experimental results, an isothermal section at $373 \mathrm{~K}$ and some isopleth section phase diagrams were considered to optimize the thermodynamic parameters of the $\mathrm{Sn}-\mathrm{Ag}-\mathrm{Sb}$ ternary system. Evaluated and adopted thermodynamic parameters were listed in Table 3. Figure 5 shows a comparison of the experimental and calculated enthalpy of mixing of the liquid phase at $1253 \mathrm{~K}$ on some vertical sections $(\mathrm{Sb} / \mathrm{Sn}=4 / 1,3 / 2,2 / 3$ and $1 / 4$ in mole fraction), which shows basic agreement between experiments and calculations. The calculated isothermal section at $373 \mathrm{~K}$ is in good agreement with the experimental phase equilibria as shown in Fig. 6. Calculated phase diagrams of the vertical sections in Fig. 7 also show satisfactory agreement with experimental data. Based on the optimized thermodynamic parameters, the liquidus projection and reaction paths were calculated in Fig. 8, in which there are three invariant reactions involving liquid. The result was summarized in Table 4.

According to the comparison between experiment and calculation in the isopleth section on 8 mass\% $\mathrm{Ag}$ shown in Fig. 7, considerable discrepancies in the thermal arrest temperatures around $508 \mathrm{~K}$ at $50-54$ mass $\%$ Sb measured by Masson et $a l .{ }^{25)}$ were observed. He mentioned that the tendency for non-equilibrium freezing in the $\mathrm{Sn}-\mathrm{Ag}-\mathrm{Sb}$ system is great, which causes the unexpected thermal arrests at low temperature. Then, the non-equilibrium solidifications are simulated by Scheil model ${ }^{26)}$ to explain this anomaly. Figure 9 shows the calculated results of solidification under equilibrium and non-equilibrium conditions of Sn-8Ag-52Sb (mass\%) alloy. In both simulation, solidification starts at $691 \mathrm{~K}$ with a primary crystal of (Sb). Under the equilibrium condition, liquid phase disappears at $643 \mathrm{~K}$, which is consistent with the calculated phase diagram shown in Fig. 7. However, tin concentrates into liquid phase with increasing solid phases under the non-equilibrium condition of Scheil model. In consequence, the terminating temperature of solidification falls drastically down to the invariant reaction, Liquid $+\mathrm{Sb}_{2} \mathrm{Sn}_{3} \Leftrightarrow \varepsilon-\mathrm{Ag}_{3}(\mathrm{Sb}, \mathrm{Sn})+(\beta \mathrm{Sn})$ at $504.5 \mathrm{~K}$, and further down to the Sn-Ag binary eutectic at
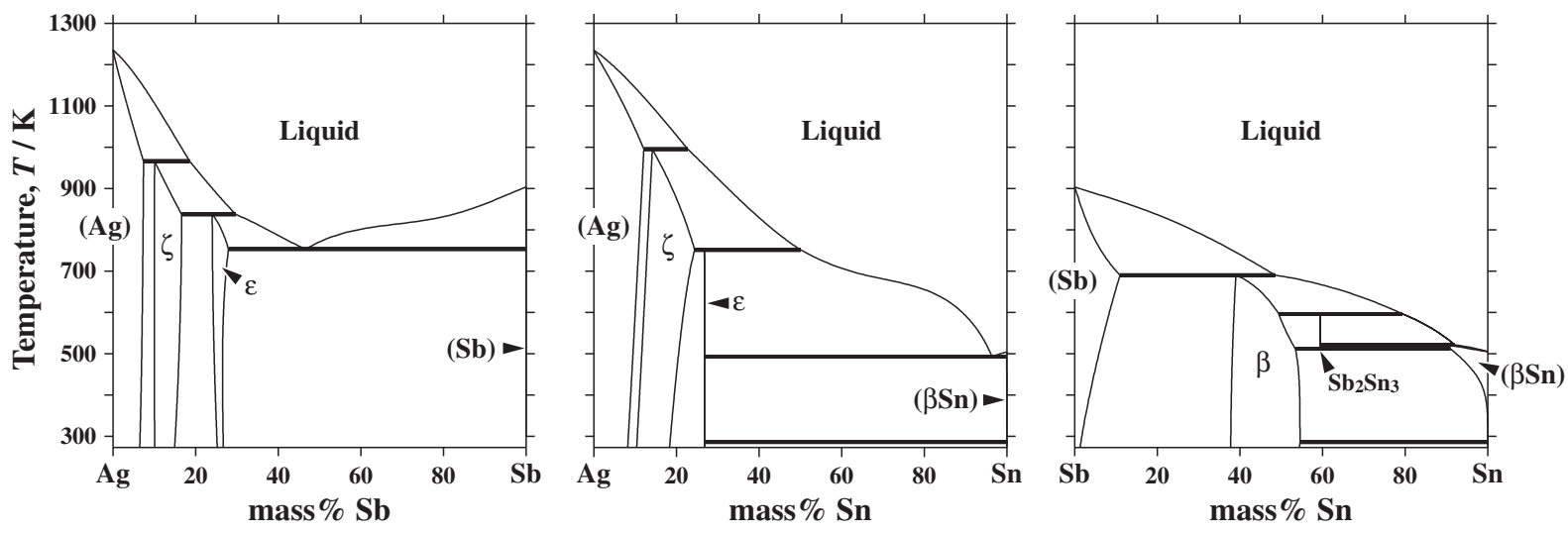

Fig. 4 Calculated $\mathrm{Ag}-\mathrm{Sb},{ }^{16)} \mathrm{Ag}-\mathrm{Sn}^{17,20)}$ and $\mathrm{Sb}-\mathrm{Sn}^{21)}$ binary phase diagrams. 
Table 3 Evaluated and adopted thermodynamic parameters in the $\mathrm{Sn}$-Ag-Sb system.

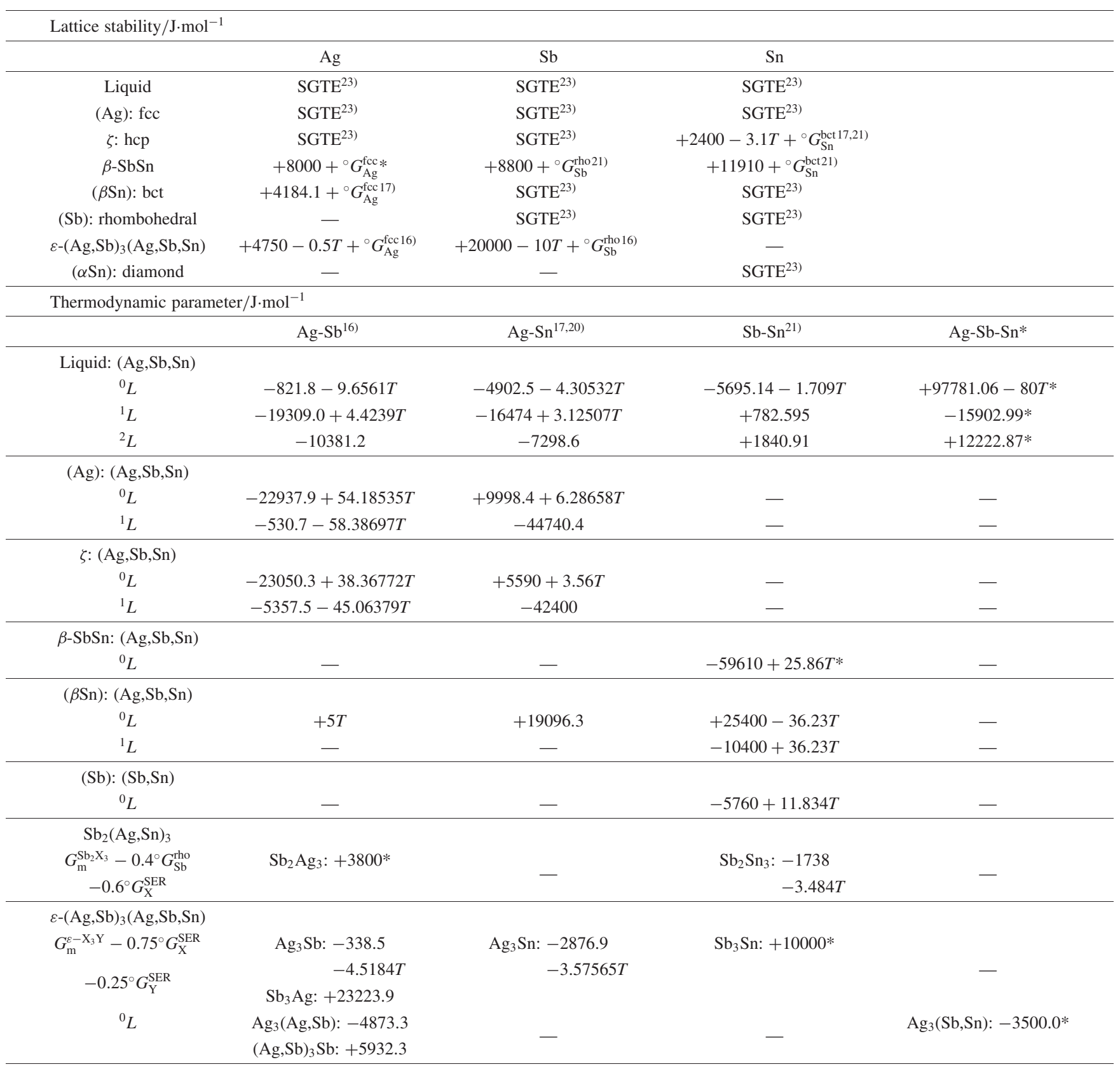

\footnotetext{
* -Evaluated value in the present work.
}

$494 \mathrm{~K}$. This must be the reason of the low arrest temperatures detected by Masson et al. ${ }^{25)}$

\subsection{Determination of density and surface tension}

The temperature dependencies of the surface tension and the density are listed in Tables 5 and 6 and the respective linear equations were determined using the least squares method. The variance analyze ${ }^{27)}$ was used for calculation of errors of surface tension and density. Temperature dependence of the surface tension of pure antimony is plotted in Fig. 10. Results of this study are close to Refs. 28 and 29 and do not exceed $10 \mathrm{mN} / \mathrm{m}$ and the agreement is contained in the experimental errors of the maximum bubble pressure method. Larger differences of about $20 \mathrm{mN} / \mathrm{m}$ are noted in comparison with Ref. 30.

Figure 11 represents the temperature dependence of the surface tension of the investigated ternary alloys in comparison with the data of binary eutectic Sn-Ag from Ref. 6. It is easily seen that the addition of antimony decreases the surface tension. The same tendency is observed for the isotherm of the surface tension plotted in Fig. 12 at the temperatures 523 and $1173 \mathrm{~K}$. In Fig. 12 solid lines are calculated from eq. (10), using Butler's model with present thermodynamic parameters. The agreement with calculated data is contained within the experimental errors of the maximum bubble pressure method.

On the proceeding two figures are represented densities. Figure 13 shows temperature dependence of the density and similarly as for the surface tension addition of antimony decreases density in comparison with density data for binary eutectic Sn-Ag. ${ }^{6}$ In Fig. 14 the experimental isotherms at two temperatures of 523 and $1073 \mathrm{~K}$ are fitted by curvilinear 


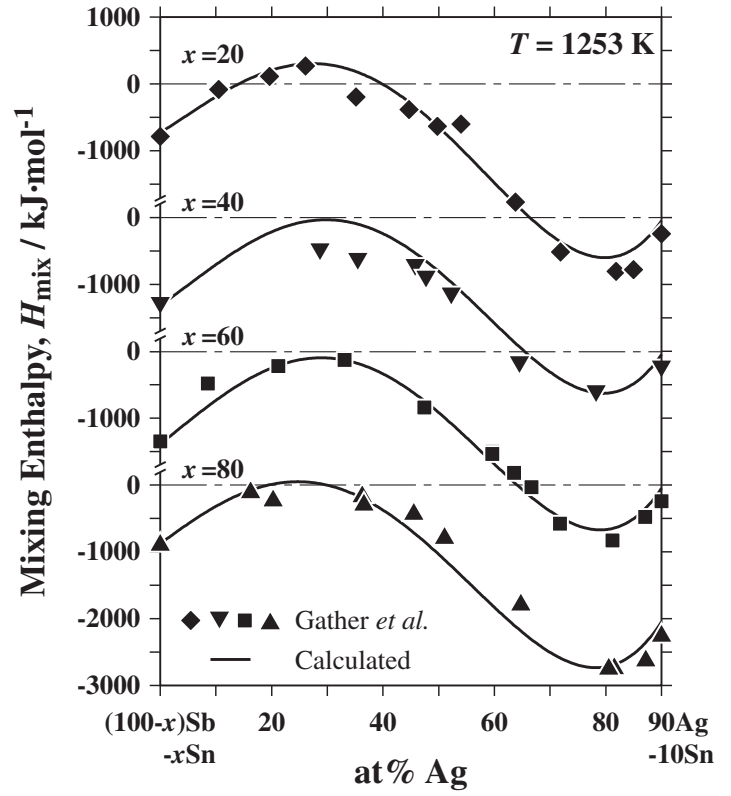

Fig. 5 Comparison between measured and calculated enthalpy of mixing of the liquid phase.

(a) 8 mass $\% \mathrm{Ag}$

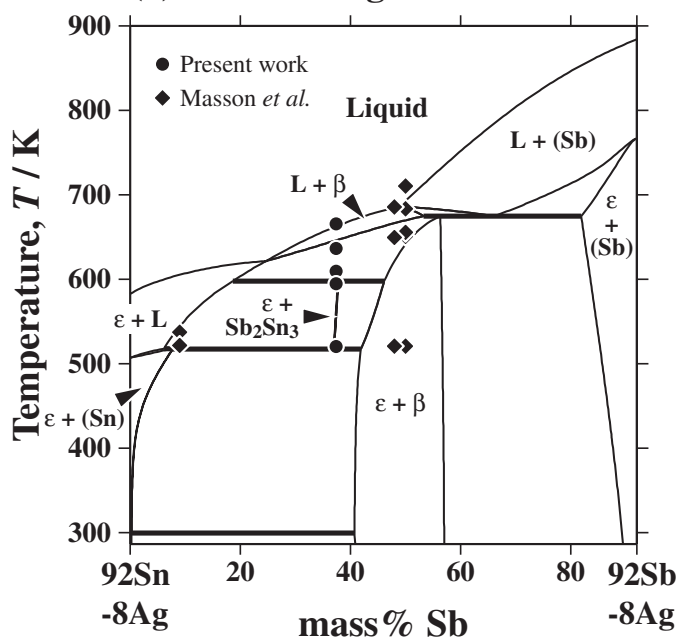

(c) 15 mass \% $\mathrm{Sb}$

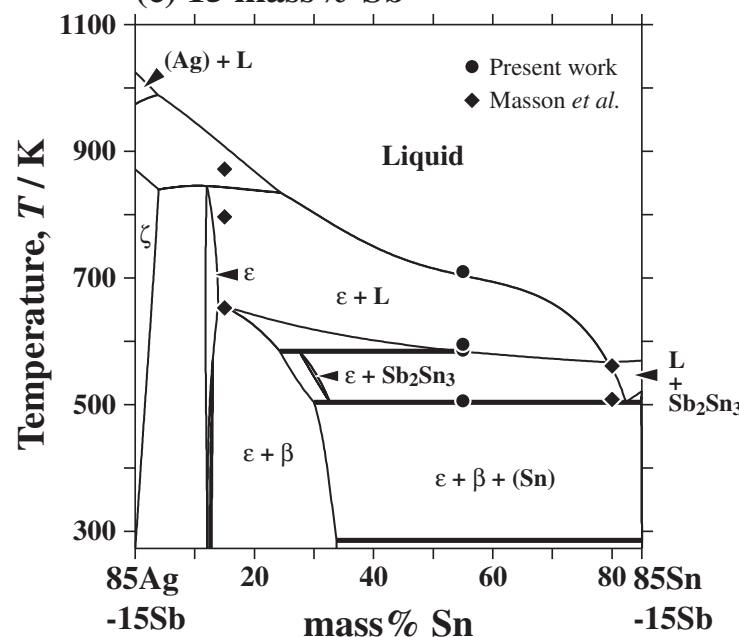

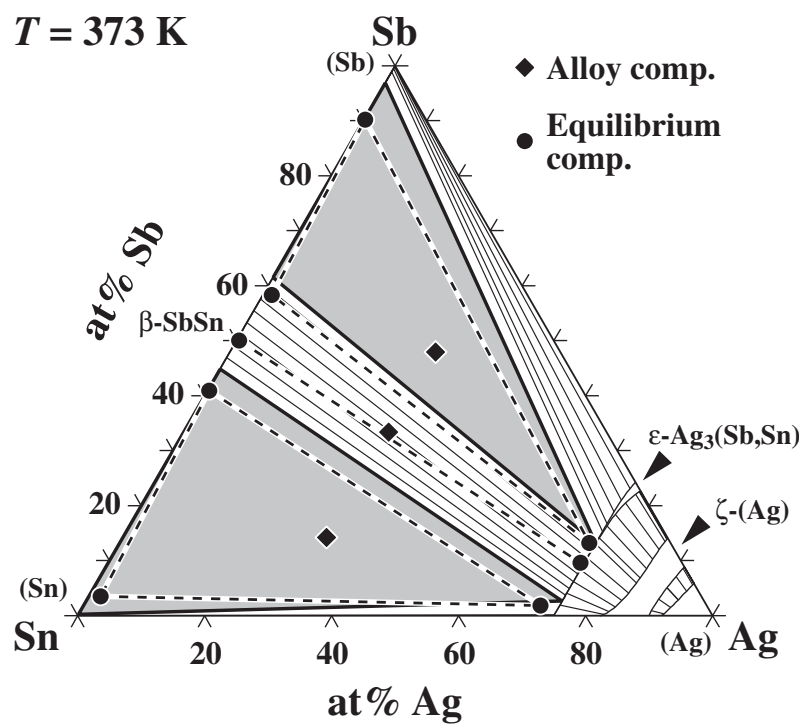

Fig. 6 Calculated phase diagram of isothermal section at $373 \mathrm{~K}$ compared with present experimental data.

(b) 30 mass \% Ag

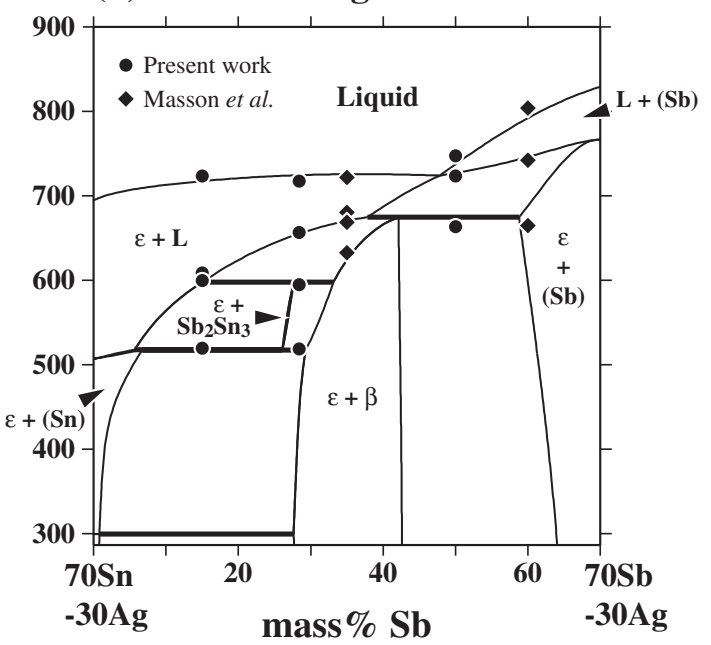

(d) 10 mass $\% \mathrm{Sn}$

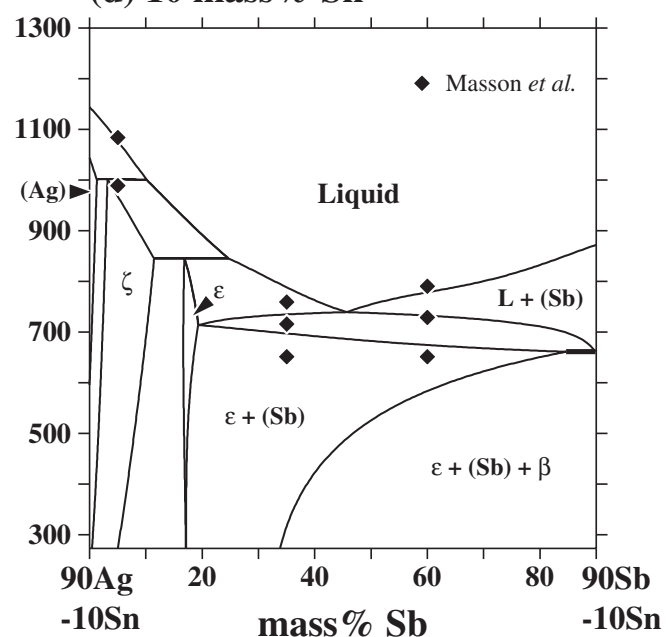

Fig. 7 Calculated phase diagrams of isopleth sections at (a) 8 mass $\% \mathrm{Ag}$, (b) $30 \mathrm{mass} \% \mathrm{Ag}$, (c) $15 \mathrm{mass} \% \mathrm{Sb}$, and (d) $10 \mathrm{mass} \% \mathrm{Sn}$ compared with present experimental data and Masson et al. ${ }^{25)}$ 
Table 4 Calculated invariant reactions in the $\mathrm{Sn}-\mathrm{Ag}-\mathrm{Sb}$ system.

\begin{tabular}{|c|c|c|c|}
\hline Invariant reaction & $\begin{array}{l}\text { Symbol } \\
\text { in Fig. } 8\end{array}$ & Temperature/K & $\begin{array}{l}\text { Liquid composition } \\
\text { (mass } \%)\end{array}$ \\
\hline Liquid $+(\mathrm{Sb}) \Leftrightarrow \varepsilon+\beta$ & PE1 & 661.2 & Sn-14.6Ag-46.1Sb \\
\hline Liquid $+\beta \Leftrightarrow \varepsilon+\mathrm{Sb}_{2} \mathrm{Sn}_{3}$ & PE2 & 584.3 & $\mathrm{Sn}-6.5 \mathrm{Ag}-18.9 \mathrm{Sb}$ \\
\hline Liquid $+\mathrm{Sb}_{2} \mathrm{Sn}_{3} \Leftrightarrow \varepsilon+(\beta \mathrm{Sn})$ & PE3 & 504.5 & $\mathrm{Sn}-3.4 \mathrm{Ag}-6.2 \mathrm{Sb}$ \\
\hline
\end{tabular}

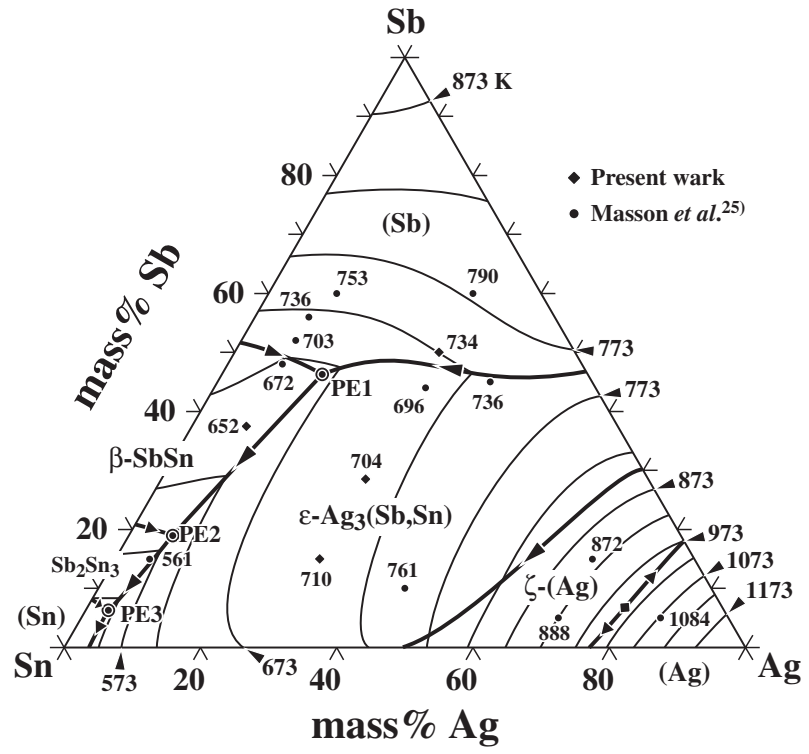

Fig. 8 Calculated liquidus projection diagram in the $\mathrm{Sn}-\mathrm{Ag}-\mathrm{Sb}$ system. The continuous thin lines denote the liquidus at individual temperatures.

dependence using the following two equations:

$$
\text { at } 525 \mathrm{~K} ; \quad \rho=7051.9-2075.7 x_{\mathrm{Sb}} \quad\left(\mathrm{kg} / \mathrm{m}^{3}\right)
$$

while

$$
\text { at } 1073 \mathrm{~K} ; \quad \begin{aligned}
\rho= & 6722.5-3618.7 x_{\mathrm{Sb}} \\
& +20024 x_{\mathrm{Sb}}^{2}\left(\mathrm{~kg} / \mathrm{m}^{3}\right)
\end{aligned}
$$

\section{Conclusion}

The phase equilibria of the Sn-Ag-Sb ternary system, including an isothermal section at $373 \mathrm{~K}$ as well as four isopleth sections were determined by EPMA and DSC, respectively.

Thermodynamic assessment of the $\mathrm{Sn}-\mathrm{Ag}-\mathrm{Sb}$ system was carried out based on the experimental data. The thermodynamic parameters for describing the Gibbs energy were optimized, resulting in good agreement between calculated and experimental values of phase equilibria and thermodynamic properties.

The surface tension and the density of the (Sn$3.8 \mathrm{at} \% \mathrm{Ag})_{\mathrm{eu}}+\mathrm{Sb}$ liquid alloys were measured using the maximum bubble-pressure method and the diametric method, respectively. The linear dependencies of surface tension and density on temperature were observed. Additionally, the surface tension was calculated based on the Butler's model and like in other previously investigated systems, the curvilinear dependence on temperature has been observed.
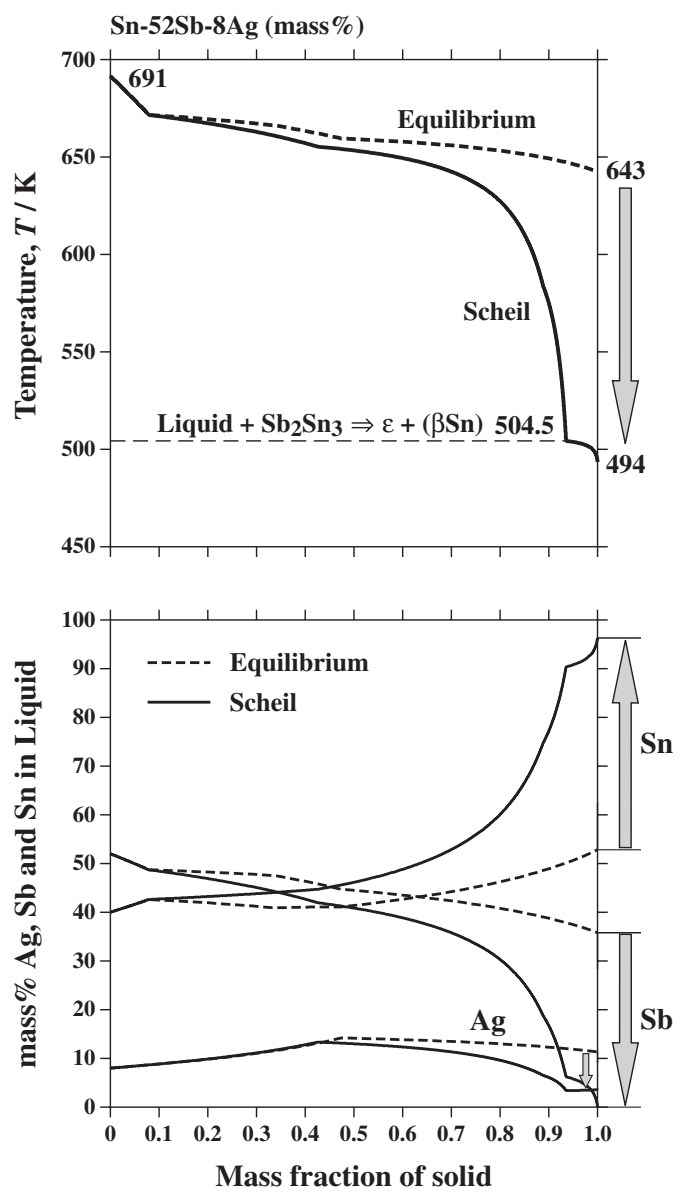

Fig. 9 Solidification simulation under equilibrium condition and Scheil model. ${ }^{26)}$

Table 5 Temperature dependencies of the surface tension of (Sn$\mathrm{Ag})_{\mathrm{eu}}+\mathrm{Sb}$ alloys together with the errors calculated for $\mathrm{A}$ and $\mathrm{B}$ parameters and the surface tension calculated at $523 \mathrm{~K}$.

\begin{tabular}{ccccc}
\hline$x_{\mathrm{Sb}}$ & $\begin{array}{c}\gamma=\mathrm{A}+\mathrm{B} T \\
/ \mathrm{mN} \cdot \mathrm{m}^{-1}\end{array}$ & $\begin{array}{c}\gamma(523 \mathrm{~K}) \\
/ \mathrm{mN}^{-1} \mathrm{~m}^{-1}\end{array}$ & $\begin{array}{c}\operatorname{Err}(\mathrm{A}) \\
/ \mathrm{mN} \cdot \mathrm{m}^{-1}\end{array}$ & $\begin{array}{c}\operatorname{Err}(\mathrm{B}) \\
/ \mathrm{mN} \cdot \mathrm{m}^{-1} \cdot \mathrm{K}^{-1}\end{array}$ \\
\hline 0.00 & $=586.4-0.0904 T$ & $539.1 \pm 12.5$ & \pm 15.6 & \pm 0.0179 \\
0.03 & $=559.8-0.0704 T$ & $523.0 \pm 6.7$ & \pm 6.7 & \pm 0.0078 \\
0.06 & $=545.9-0.0614 T$ & $513.8 \pm 7.0$ & \pm 6.6 & \pm 0.0075 \\
0.09 & $=538.0-0.0578 T$ & $507.7 \pm 11.9$ & \pm 12.9 & \pm 0.0136 \\
$1.00^{*}$ & $=419.0-0.0561 T_{\mathrm{m}}$ & $368.3 \pm 3.9$ & \pm 10.7 & \pm 0.0100 \\
\hline
\end{tabular}

$*-\gamma$ of Sb calculated at melting temperature $(904 \mathrm{~K})$

Table 6 Temperature dependencies of the density of of $(\mathrm{Sn}-\mathrm{Ag})_{\mathrm{eu}}+\mathrm{Sb}$ alloys together with the errors calculated for A and B parameters and the density calculated at $873 \mathrm{~K}$.

\begin{tabular}{ccccc}
\hline$x_{\mathrm{Sb}}$ & $\begin{array}{c}\rho=\mathrm{A}+\mathrm{B} T \\
/ \mathrm{kg} \cdot \mathrm{m}^{-3}\end{array}$ & $\begin{array}{c}\rho(873 \mathrm{~K}) \\
/ \mathrm{kg} \cdot \mathrm{m}^{-3}\end{array}$ & $\begin{array}{c}\text { Err (A) } \\
/ \mathrm{kg} \cdot \mathrm{m}^{-3}\end{array}$ & $\begin{array}{c}\text { Err (B) } \\
/ \mathrm{kg} \cdot \mathrm{m}^{-3} \cdot \mathrm{K}^{-1}\end{array}$ \\
\hline 0.00 & $=7364.5-0.599 T$ & $6842 \pm 27$ & \pm 40 & \pm 0.047 \\
0.03 & $=7316.5-0.637 T$ & $6760 \pm 58$ & \pm 122 & \pm 0.159 \\
0.06 & $=7288.0-0.663 T$ & $6709 \pm 75$ & \pm 123 & \pm 0.156 \\
0.09 & $=7141.8-0.543 T$ & $6668 \pm 75$ & \pm 120 & \pm 0.127 \\
\hline
\end{tabular}




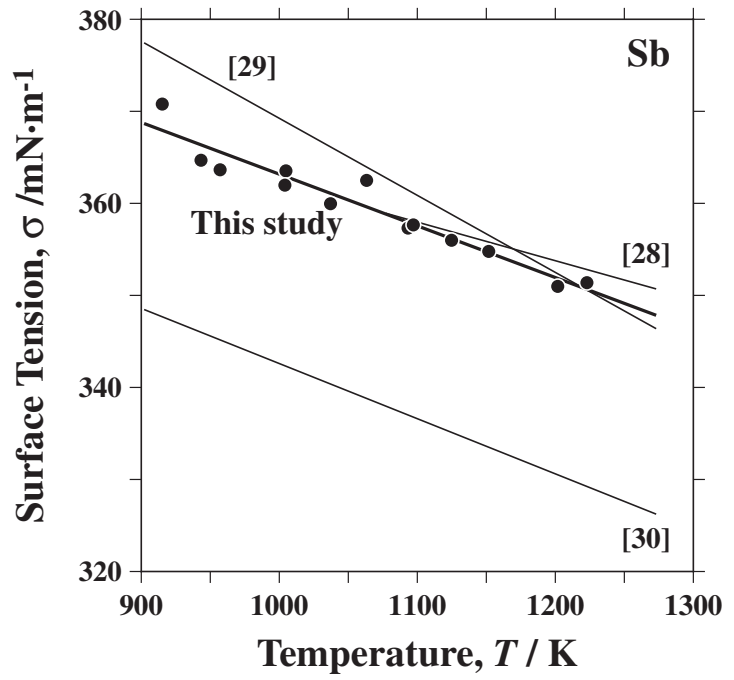

Fig. 10 Surface tension of antimony in comparison with the data from Refs. 28-30.

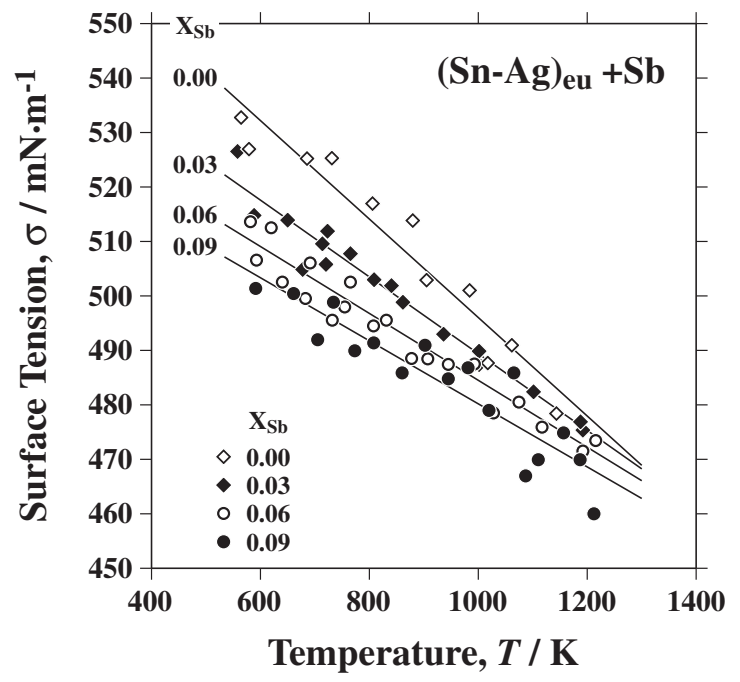

Fig. 11 Temperature dependencies of the surface tension of $(\mathrm{Sn}-\mathrm{Ag})_{\mathrm{eu}}+\mathrm{Sb}$ liquid alloys. Symbols are referred to experimental data and the solid lines are calculated from equations in Table 5 .

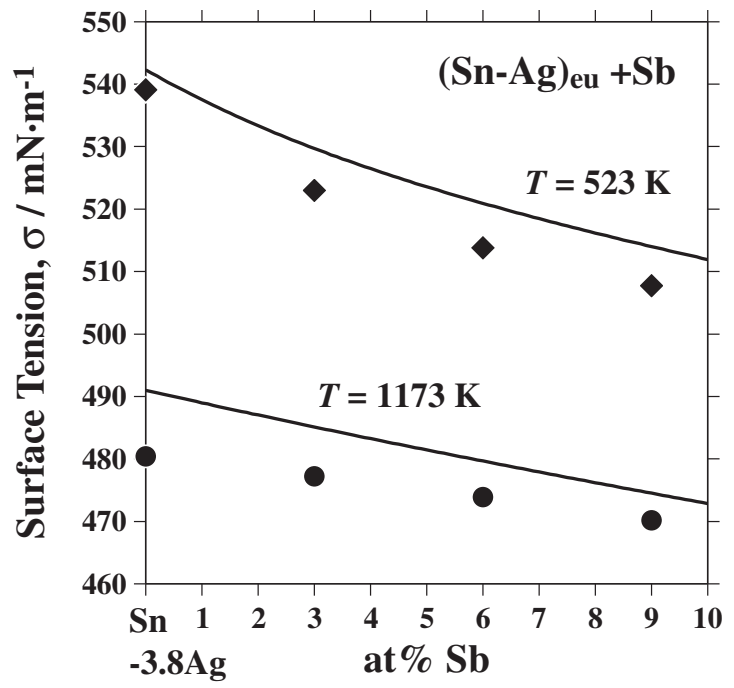

Fig. 12 Surface tension isotherms calculated at 523 and 1073 K. Symbols represent the values calculated from equations in Table 5. Continuous lines show the values calculated from Butler's model. ${ }^{4)}$

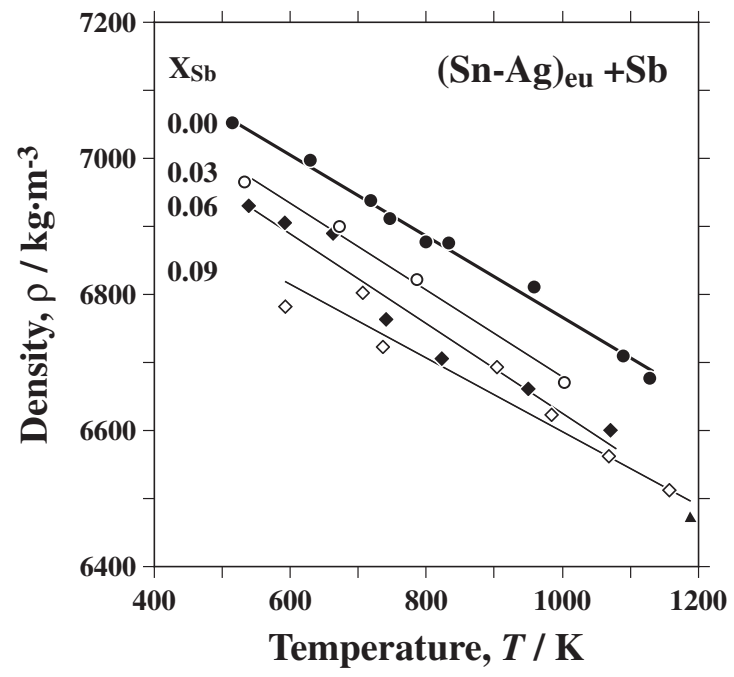

Fig. 13 Temperature dependencies of density of $(\mathrm{Sn}-\mathrm{Ag})_{\mathrm{eu}}+\mathrm{Sb}$ liquid alloys. Symbols are referred to experimental data and the values calculated from equations in Table 6 show the continuous lines.

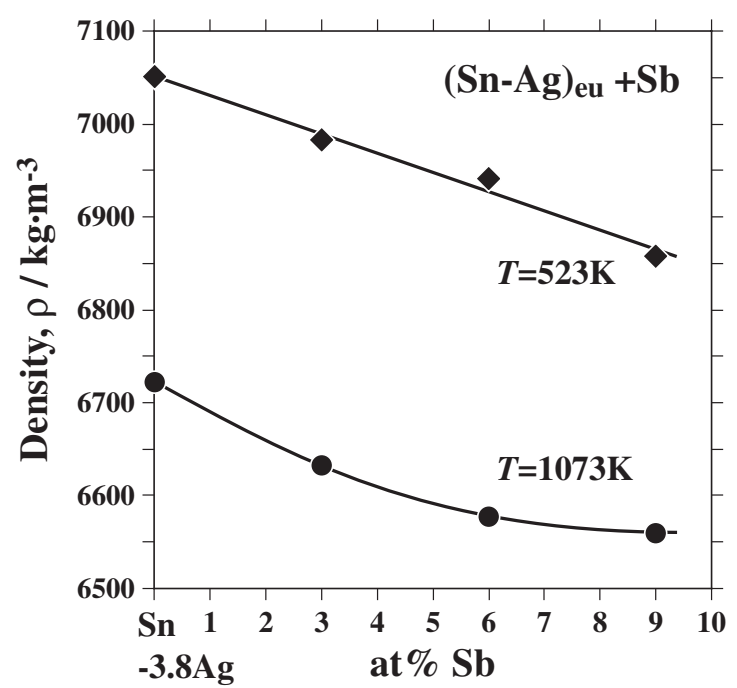

Fig. 14 Isotherms of the density of $(\mathrm{Sn}-\mathrm{Ag})_{\mathrm{eu}}+\mathrm{Sb}$ liquid alloys at 523 and $1073 \mathrm{~K}$. Symbols referred to the experimental data and continuous lines show the values calculated at 523 and $1073 \mathrm{~K}$ from eqs. (13) and (14).

\section{REFERENCES}

1) Z. Moser, W. Gasior, J. Pstrus, W. Zakulski, I. Ohnuma, X. J. Liu, Y. Inohana and K. Ishida: J. Electronic Mater. 30 (2001) 1120-1128.

2) X. J. Liu, Y. Inohana, I. Ohnuma, R. Kainuma, K. Ishida, Z. Moser, W. Gasior and J. Pstrus: J. Electronic Mater. 31 (2002) 1139-1151.

3) Z. Moser, W. Gasior and J. Pstrus: Inzynieria Materialowa 2 (2002) 6568.

4) J. A. V. Butler: Proc. R. Soc. London Ser. A 135 (1932) 348-375.

5) W. Gasior, Z. Moser, J. Pstrus, B. Krzyzak and K. Fitzner: J. Phase Equilib. 2 (2003) 21-39.

6) W. Gasior, Z. Moser and J. Pstrus: J. Phase Equilib. 22 (2001) 20-25

7) Z. Moser, W. Gasior and J. Pstrus: J. Phase Equilib. 22 (2001) 254-258.

8 Z. Moser, W. Gasior, J. Pstrus and S. Ksiezarek: J. Electronic Mater. 31 (2002) 1225-1229.

9) I. Ohnuma, M. Miyashita, K. Anzai, X. J. Liu, H. Ohtani and K. Ishida: J. Electron Mater. 29 (2000) 1137-1144.

10) B. J. Lee and H. M. Lee: Design and Reliability of Solders and Solder Interconnections, eds. R. K. Mahidhara, D. R. Frear, S. M. L. Sastry, K. L. Murty, P. K. Liaw and W. Winterbotoom, (The Minerals, Metals and 
Materials Society, 1997).

11) S. Sugden: J. Chem. Soc. 124 (1924) 858-868.

12) T. Tanaka and T. Iida: Steel Res. 65 (1994) 21-28.

13) T. Tanaka, K. Hack, T. Iida and S. Hara: Z. Metallk. 87 (1996) 380 389.

14) T. Tanaka, K. Hack and S. Hara: MRS Bull. 24 (1999) 45-50.

15) B.-Z. Lee, C.-S. Oh and D. N. Lee: J. Alloy. Compd. 215 (1994) 293 301.

16) C.-S. Oh, J.-H. Shim, B.-J. Lee and D. N. Lee: J. Alloy. and Compd. 238 (1996) 155-166.

17) I. Karakaya and W. T. Thompson: Bull. Alloy Phase Diagram 8 (1987) 340-347.

18) P.-Y. Chevalier: Thermochim. Acta 136 (1988) 45-54.

19) U. R. Kattner and W. J. Boettinger: J. Electronic Mater. 23 (1994) 603 610

20) H. Ohtani, I. Satoh, M. Miyashita and K. Ishida: Mater. Trans. 42
(2001) 722-731.

21) H. Ohtani, K. Okuda and K. Ishida: J. Phase Equilib. 16 (1995) 416429.

22) B. Jönsson and J. Ågren: Mater. Sci. Technol. 2 (1986) 913-916.

23) A. T. Dinsdale: CALPHAD 15 (1991) 317-425.

24) B. Gather, P. Schröter and R. Blachnik: Z. Metallk. 78 (1987) 280-285.

25) D. B. Masson and B. K. Kirkpatrick: J. Electronic Mater. 15 (1986) 349-353.

26) E. Scheil: Z. Metallk. 34 (1942) 70-72.

27) W. Volk: Applied Statistics for Engineers, 2nd Edition, (McGraw-Hill Book Comp., 1969).

28) I. Lauerman and F. Sauerwald: Z. Metallk. 55 (1964) 605-612.

29) V. Somol and M. Beranek: Sb. Vysk. Sk. Chem.-Technol. Praze Anorg. Chem. Technol. B30 (1984) 199-205.

30) V. B. Lazarev: Russ. J. Phys. Chem. 38 (1964) 325-330. 